\title{
MEGALOCYTIC DEFICIENCY ANAEMIA CURED BY SMALL AMOUNTS OF FRESH ENDIVE
}

\author{
BY \\ G. M. H. VEENEKLAAS \\ From the University Paediatric Department, the Wilhelmina Hospital for Sick Children, Utrecht, The Netherlands
}

(RECEIVED FOR PUBLCATION OCTORER 21, 1951)

Megalocytic anaemia in childhood is an unusual disease in The Netherlands. Routine examination of the bone marrow of anaemic patients rarely reveals the existence of this type, and is probably due to an adequate number of clinies, which give advice to the majority of the mothers on the infant's diet during the first year of life. The continued functioning of these clinics during the German occupation may explain the absence of an increase of the anaemias during that period. During the last 10 years we have seen only four patients, in whom an exclusive diet of goat's or cow's milk led to the development of dystrophy and megalocytic anaemia at the age of about 1 year. Attention was drawn to this form of anaemia with its characteristic bone marrow findings (Veeneklaas, 1940, 1942). At that time it was possible to prove that fresh vegetables and/or fresh fruit contained substances which were able to cure this anaemia. It was shown (Veeneklaas, 1943 and 1947), and in 1949 and 1950 it was confirmed, that these substances were present in fresh endive.

Megalocytic anaemia had been described before. In 1909 von Starck published the first case, and Faber and Bachman in 1928 and 1936 were able to collect 20 cases from the literature. Meanwhile the fact was noticed that these children often suffered from infections of the upper respiratory tract and sometimes had diarrhoea, and liver therapy caused a reticulocyte crisis and recovery without relapse. Later folic acid (Zuelzer and Ogden, 1946) and vitamin $B_{12}$ (McPherson, Jonsson and Rundles, 1949) were found to exert the same influence. The pathogenesis of these anaemias is still uncertain. Somewhere in the chain of supply, absorption, transport, storage, liberation, consumption and excretion of the anti-anaemic substances a link may drop out, which is not necessarily always the same.

\section{Case Reports}

Case 1. The normal pregnancy of a healthy primiparous woman ended on December 21, 1937, in the birth of a normal child weighing about $3,000 \mathrm{~g}$. The child was breast-fed for six weeks, and was then put on cow's milk, with the addition of water and sugar and later flour, in the correct amounts. After six months he was given cooked vegetables in the milk formula. Until the eighth month he developed well, but at that time anorexia started and pallor was noted. At the age of 12 months he had pneumonia and the haemoglobin was $45 \%$. Treatment with iron and ascorbic acid in large doses did not influence either the anorexia or the anaemia. The child lived in an institution, which for 16 years had taken care of 70 children a year in a similar way. A syndrome such as that described had never occurred in the home during the whole time.

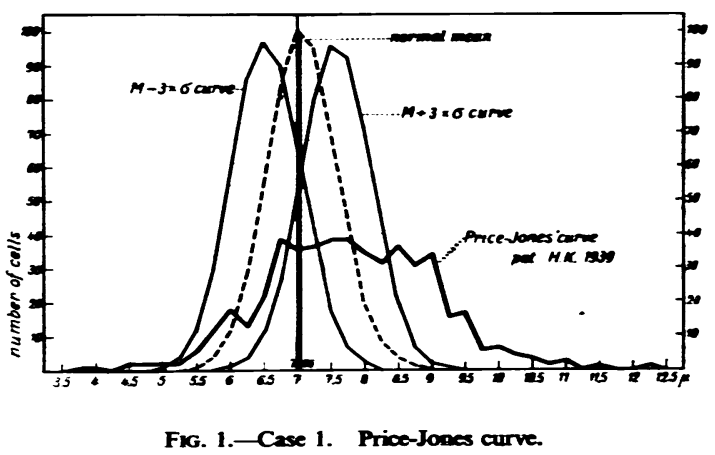

In March, 1939, the child was admitted to hospital. At the age of 15 months the patient was $70 \mathrm{~cm}$. tall and weighed 6,600 g. There was marked dystrophy, apathy and pallor. On the forehead and on the temples there was a thick growth of downy hair. The lymph nodes were all just palpable; the mouth and tongue showed no abnormalities. The heart and lungs seemed normal. The liver and spleen could be felt. Values for free and total acidity were: fasting, $0 / 30$, after one hour, trace /10, after two hours, 10/22.

Haemoglobin was $42 \%$, erythrocytes were $1,650,000$ per c.mm. There was anisocytosis, poikilocytosis and polychromasia. The colour index was 1-3. A Prico-Jones curve (Fig. 1) demonstrates the size of the erythrocytes. Reticulocytes were $0.7 \%$ and leucocytes $7,150 /$ c.mm., of which 5,400 were lymphocytes. Thrombocytes were 38,000/c.mm. and the bilirubin level was $0.74 \mathrm{mg} . \%$. Fragility started at $0.45 \%$, and was 


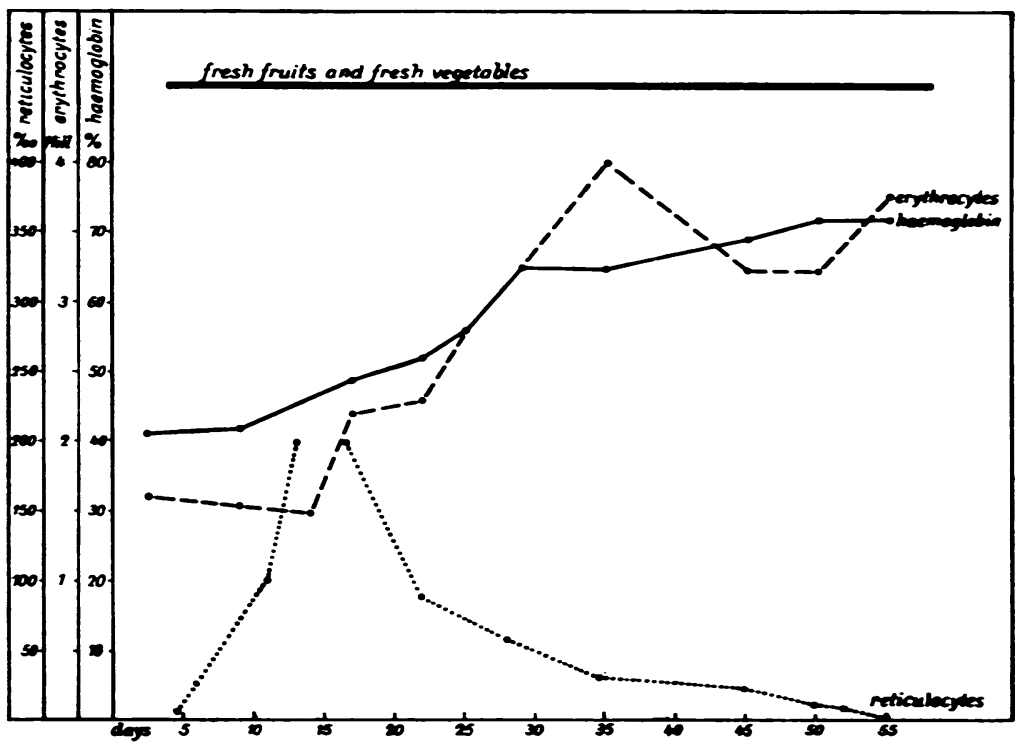

Frg. 2.-Case 1. Reticulocyte crisis and improvement infbloodfoount.

weighed $3,250 \mathrm{~g}$. The child was immediately put on a cow's milk formula with the correct addition of water, sugar and flour. The parents were intelligent people, who would have given their child a complete diet but who, as Jews during the German occupation, were restricted in their movements. The only possible supplementary food was the juice of preserved endive, which was given sporadically after the sixth month. Infections did not occur. Development was normal until the ninth month, then anorexia started and pallor was noted. The child was given iron and ascorbic acid but without effect. At the time of treatment in 1942 the patient was 11 months old; the height was $71 \mathrm{~cm}$., but the weight was unknown because there were

complete at $0.32 \% \mathrm{Na}$. Cl. The bone marrow picture was megaloblastic. Treatment consisted of the addition of large amounts of fresh vegetables and fresh fruit to the diet which the child previously had. After 10 days a reticulocyte crisis of over $20 \%$ followed (Fig. 2). After four weeks the haemoglobin was $66 \%$. Ten weeks later the weight had increased to $9,000 \mathrm{~g}$., the downy hair had disappeared, liver and spleen were no longer palpable, haemoglobin was $80 \%$, erythrocytes $4,540,000 /$ c.mm., leucocytes $9,850 /$ c.mm., of which 5,320 were lymphocytes. The bone marrow picture had become completely normal. Relapse did not occur.

Evaluation of the treatment was made difficult by the addition of more than one green vegetable to the original diet.

Case 2. In June, 1941, a healthy mother was delivered of her first child, a girl, who was normal and

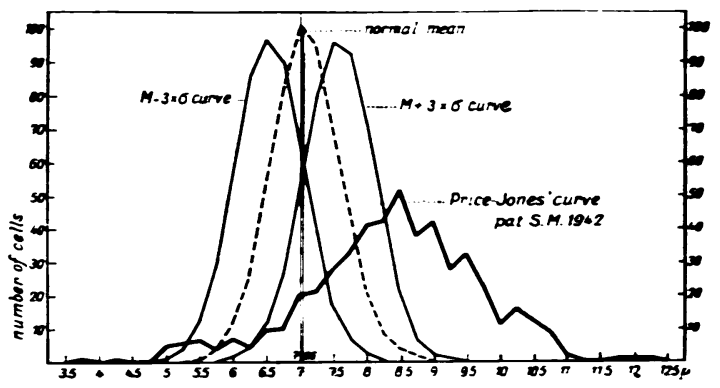

Fig. 3.-Case 2. Price-Jones curve. no scales at home. The patient was a markedly dystrophic, apathetic child with a flabby skin and intense pallor. A few lymph nodes were palpable in the neck and the inguinal region. Nothing abnormal was noted in the mouth, tongue, heart or lungs. The liver and spleen were just palpable. Values for free and total acidity were: fasting $15 / 20$, and after half hour $25 / 35$. The blood bilirubin level was $0.8 \mathrm{mg} . \%$. Fragility began at 0.46 and was complete at $0.34 \%$ Na. Cl. The faeces contained $26 \%$ fat. Haemoglobin was $28 \%$, erythrocytes were $1,090,000 /$ c.mm., and there was anisocytosis, poikilocytosis and anisochromia. The colour index was 1.28. A Price-Jones curve (Fig. 3) demonstrates the erythrocyte diameter. Reticulocytes were $0.9 \%$, leucocytes $7,900 /$ c.mm., of which 5,800 were lymphocytes. Thrombocytes were 74,000 / c.mm. The bone marrow was megaloblastic. The ascorbic acid content of the blood was $1 \cdot 1 \mathrm{mg} . \%$. As a safety measure the child was treated at home. The only treatment consisted of the addition of $200 \mathrm{~g}$. fresh endive daily to the existing diet. After 12 days reticulocytes had increased to $30 \%$ (Fig. 4). After 30 days the haemoglobin was $60 \%$ and the anaemia had become normocytic. The general condition had improved considerably. Recovery was uneventful; there was no relapse.

In this patient the experimental conditions were ideal, as surrounding and dietary circumstances remained constant, which made it certain that the results were due to treatment.

Case 3. On February 27, 1949, a normal pregnancy ended after normal delivery with the birth of a child, a boy, weighing $3,200 \mathrm{~g}$. He was the second child. The first was raised on goat's milk with excellent results. 
This child was breast fod for the first three months and gained weight satisfactorily. He was then given supplementary feeds of goat's milk in increasing quantities (with water, sugar and flour), till at the age of 5 months he was given goat's millk exclusively. He also received tomato juice from 5 months. During the last three or four months the appetite had gone, the child vomited from time to time, and became increasingly pale. There had been no infections except for a cold in the previous few weeks.

On admission on October 27, 1949, the child was 8 months old, weighed $6,400 \mathrm{~g}$ and was $67 \mathrm{~cm}$. tall. He appeared ill, was dystrophic, listless and severely anaemic. A systolic murmur was heard over the heart, the liver extended one and a half fingerbreadths under the costal margin, the spleen could not be palpated. The temperature

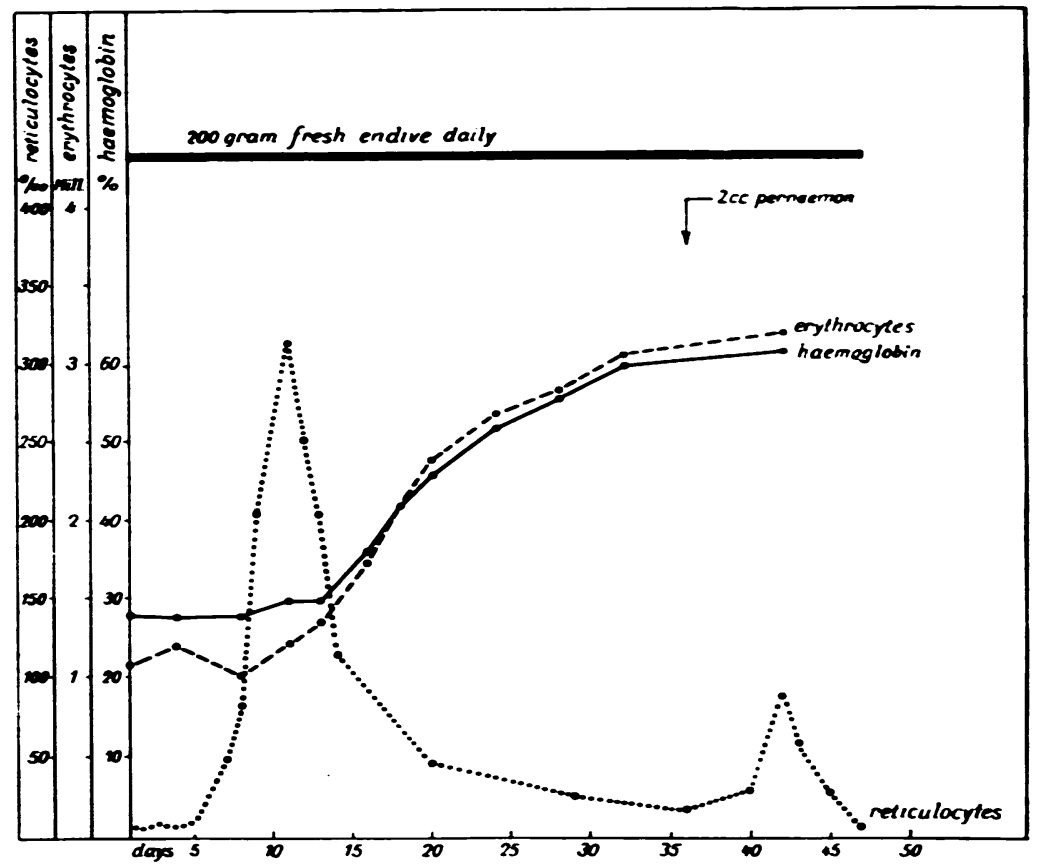
was $38.5^{\circ} \mathrm{C}$. and remained elevated during the first few days. There were no other abnormalities. Haemoglobin was $22 \%$. Erythrocytes were $800,000 /$ c.mm., with anisocytosis, poikilocytosis, polychromasia ; the colour index was 1 - 25. The Price-Jones curve (Fig. 5) demonstrates the size and the scattering of the erythrocytes. Reticulocytes were 1.6\%. Levoocytes were 17,200/c.mm., (myelocytes 2, band forms 2 , polymorphs 21 , eosinophils 4 , lymphocytes 70 , monocytes 1, erythroblasts 12). Thrombocytes were $1,008,000 /$ c.mm. The bone marrow was megaloblastic.

Immediately on admission the child was given a transfusion of $100 \mathrm{ml}$. whole blood. Haemoglobin was $38 \%$ on the next day. The diet consisted of goat's milk, with water, flour and sugar added in suitable quantities; at the same time $100 \mathrm{~g}$. of fresh endive

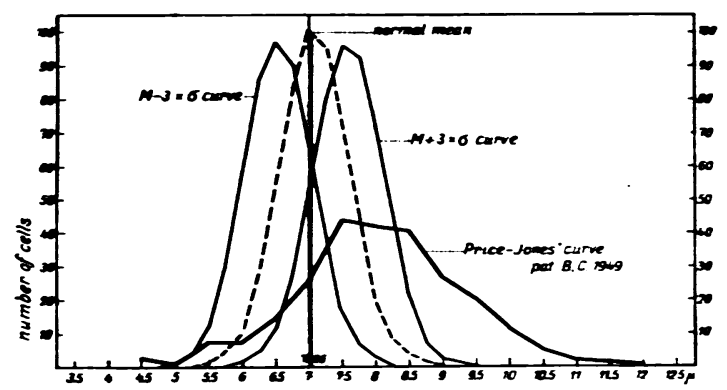

Fig. 5.-Case 3. Price-Jones curve.

daily was added. After eight days a reticulocyte crisis was noted of $15.6 \%$ (Fig. 6). After three weeks haemoglobin was $60 \%$ with $3,740,000 /$ c.mm. erythrocytes, the weight increasing in the meantime by $730 \mathrm{~g}$. The general condition had improved remarkably, in spite of an upper respiratory infection. The patient was discharged on December 17, 1949, with a haemoglobin of $75 \%$ and $4,350,000$ erythrocytes $/$ c.mm.

Three weeks after admission the child was put on an adequate diet: two weeks later it was started on oral lactas ferrosus.

During long-continued feeding with goat's milk exclusively megalocytic hyperchromic anaemia developed, which was treated by adding a daily dose of $100 \mathrm{~g}$. fresh endive to the goat's milk diet, and cleared up with a reticulocyte crisis.

Case 4. On January 12, 1950, this child, a boy and the first of healthy parents, was born normally after an uneventful pregnancy, with a birth weight of $2,500 \mathrm{~g}$. He was artificially fed, correctly in quantity and quality, but often refused fruit juice and never took vegetables, Development was normal up to the age of 6 months. After that the patient started to vomit with increasing frequency. Before admission the child was feverish.

On October 9, 1950, the child was admitted to hospital. He was then 10 months old, weighed $6,430 \mathrm{~g}$. and was $67 \mathrm{~cm}$. tall. He looked ill, apathetic and pale; the nutritional condition was adequate, the temperature was $38.3^{\circ} \mathrm{C}$. There was infection of the upper respiratory tract. A systolic murmur was heard over 


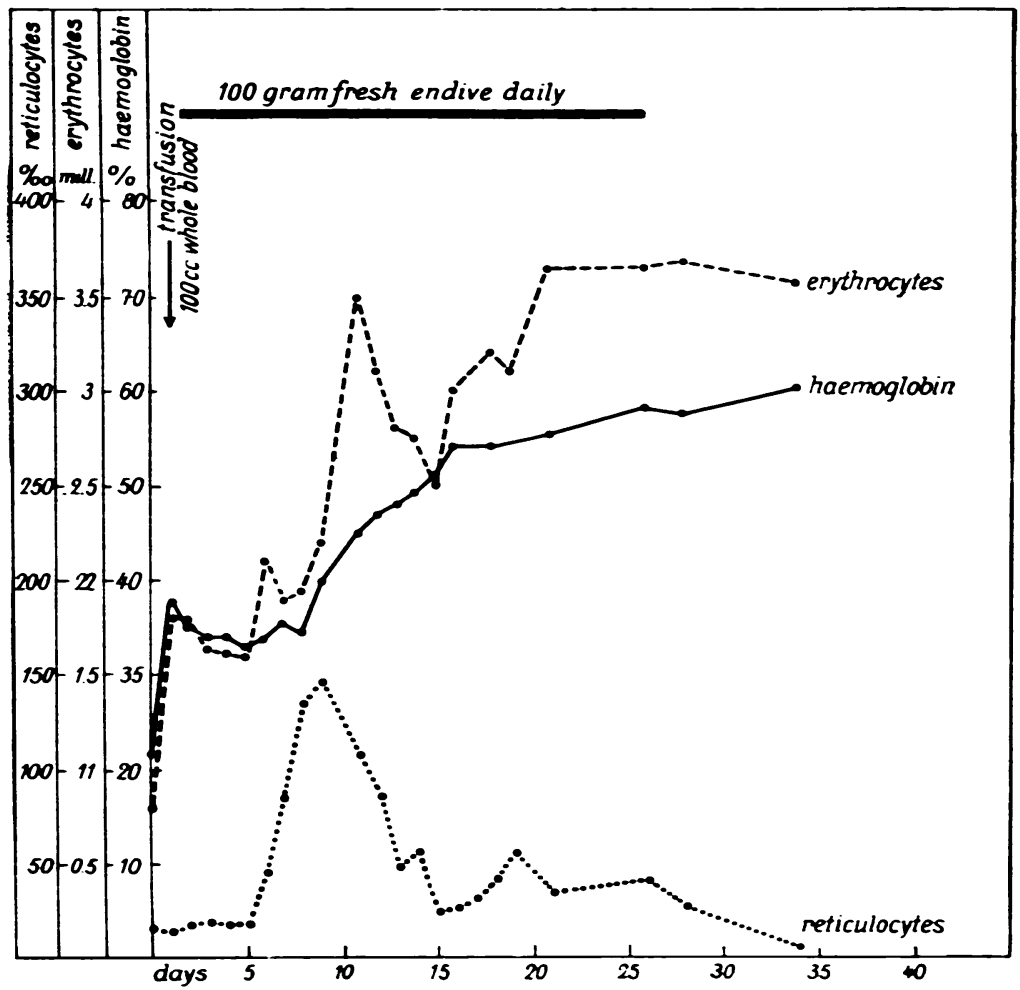

Fig. 6.-Case 3. Reticulocyte crisis and improvement in blood count.

Thrombocytes were $12,200 / \mathrm{c} . \mathrm{mm}$. The coagulation time was 1 minute and the bleeding time 4 minutes 45 seconds. The bone marrow was megabblastic.

The diet of the patient was left unchanged; it consisted of milk, $700 \mathrm{ml}$., water 200 ml., flour $60 \mathrm{~g}$., sugar $20 \mathrm{~g}$. divided over four feeds. Also 1,000 I.U. of vitamin $D$ and 1,000 I.U. of vitamin A were given. To this was added 25 g. fresh minced endive.

After one week of treatment the condition and behaviour changed completely and a reticulocyte crisis occurred (Fig. 8). In this week the child became lively and interested in his surroundings. After $\mathbf{2 0}$ days the haemoglobin was $63 \%$. and the number of red cells $3,700,000 / \mathrm{c} . \mathrm{mm}$. The weight had increased by $250 \mathrm{~g}$. Endive was. then discontinued and the child was put on a diet adequate for his age. The haemoglobin level, from then on, increased only very slowly. Iron

the heart. Breathing was normal. The liver, spleen and lymph nodes were not enlarged. On the left cheek there was a blue spot $(2 \mathrm{~cm}$. diameter). Examination of urine, faeces and cerebrospinal fluid was negative.

Haemoglobin was $27 \%$, erythrocytes were $1,220,000 /$ c.mm., with anisocytosis, poikilocytosis, polychromasia. The colour index was 1-16. A Price-Jones curve demonstrates the size and scattering of the red cells (Fig. 7). Reticulocytes were 2\%. The E.S.R. was $5 \mathrm{~mm}$. Leucocytes were 6,900/c.mm. (4,623 lymphocytes). A differential count gave band forms 2, polymorphs 26, lymphocytes 67 , monocytes 4 .

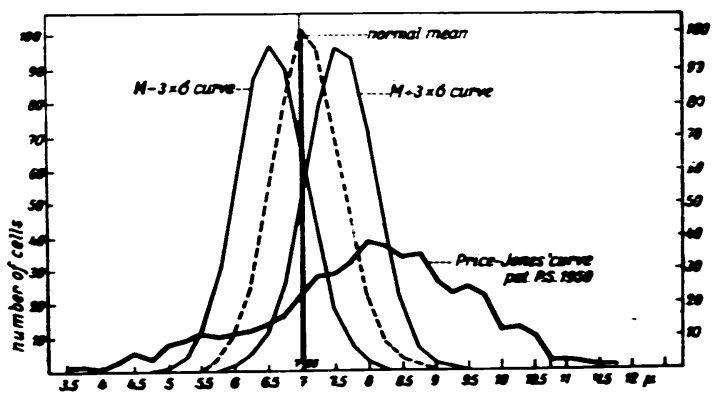

Fig. 7.-Case 4. Price-Jones curve. preparations had little effect. After $\mathbf{5 0}$ days the patient was discharged with a haemoglobin of $77 \%$ and 5,250,000 erythrocytes/c.mm.

The experimental conditions in this case were correct. The recovery could be ascribed to the fresh endive added to the original diet.

\section{Discussion}

Considering the influence of fresh endive on the condition resulting from a long-continued exclusively milk diet, it is of interest to know the folic acid content of this vegetable. This is, when fresh, 0.62-0.75y/g. (Fager, Olson, Burris and Elvehjem, 1949). Case 2 received $200 \mathrm{~g}$. fresh endive, which amounts to 124-150 $\gamma$ folic acid per day, Case 3 received only 62-75 $\gamma$ daily, Case $4,15-19 \gamma$ daily. This is a few hundred times less than the amount with which a reticulocyte crisis and recovery are usually effected in these patients. It is improbable that differences in folic acid content of this order exist between American and Dutch endive. It is therefore doubtful whether reaction and recovery in our patients, during treatment with fresh vegetables and fruit or fresh endive, is attributable to its content of folic acid alone. It seems probable that another substance is involved. If guinea-pigs 
develop scurvy on a diet entirely free of ascorbic acid and are then fed the same diet either with the addition of ascorbic acid or of tomato juice, a similar incongruity is encountered. In order to effect the same degree of recovery more crystalline vitamin $C$ is needed than is contained in the tomato juice in its natural state. In this connexion the work of May, Nelson, Lowe and Salmon (1950) is of interest, as they point out that vitamin C deficiency may also play a role in the development of megalocytic anaemia. The findings in Cases 1 and 2 do not appear to confirm this, as they had received ample vitamin $C$, but this was only given when the anaemia had already developed. It is after all possible that May's explanation holds

good for these patients. If it is indeed possible to cure this anaemia by the combined administration of folic acid and vitamin C, it is still remarkable that these are needed in very small amounts. The vitamin C content of endive is $12 \mathrm{mg} . \%$. The last patient received only $3 \mathrm{mg}$. vitamin $C$ per day. Thirty-one days after the beginning of treatment, the vitamin $\mathrm{C}$ content of the blood was determined, and was $0.2 \mathrm{mg} \%$. It seems indicated to treat such patients with similarly small doses of crystalline folic acid and vitamin $\mathbf{C}$. But the possibility is by no means excluded that endive contains traces of other substances which aid in accelerating the curative process.

\section{Summary}

Four cases of megalocytic hyperchromic deficiency anaemia are described occurring at the end of the first year of life. One of these patients had been fed exclusively on goat's milk; three had had a long-continued diet of cow's milk. All patients promptly and definitely recovered, with a reticulocyte crisis. Treatment varied: the first patient recovered with the addition of fresh vegetables and fresh fruit to the previous diet (1939). The second patient was cured by means of a dosage of $200 \mathrm{~g}$. fresh endive added to the preceding diet, the third received $100 \mathrm{~g}$. endive with his diet and the fourth only got $25 \mathrm{~g}$. fresh endive with the same diet as before.

Fresh endive apparently contains substances which are able to cure megalocytic hyperchromic anaemia. The folic acid content of fresh endive is 62-75 $\gamma$ per $100 \mathrm{~g}$. and its vitamin $C$ content is $12 \mathrm{mg} . \%$. The last patient received only $15-19 \gamma$ folic acid and $3 \mathrm{mg}$. vitamin $\mathrm{C}$ daily. The possibility that other substances contributed to this cure must be considered.

\section{REFERENCES}

Bachman, A. L. (1936). Amer. J. Dis. Child., 52, 633.

Faber, H. K. (1928). Ibid., 36, 1121.

Fager, E. E. C., Okson, O. E., Burris, R. H. and Elvehjem, C. A (1949). Food Res., 14, 1.

McPherson, A. Z. Jonsson, U. and Rundles, R. W. (1949). J.

May, C. D., Netson, E. N., Lowe, C. U. and Salmon, R. J. (1950). Amer. J. Dis. Child., 80, 191.

Starck. W. von (1909). Jb. Kinderheilk., 69, 264.

Veencklaas, G. M. H. (1940). Ned. T. Geneesk., 84, 3860 and 4517 (1942). Folia hoemat., Lpz., 65. 303.

(1943). Ned. T. Geneesk., 87, 1670.

(1947). Ibid., 11,316

Zueber, W. W. and Ögden, F. N. (1946). Amer. J. Dis. Child., 71, 211 . 